\title{
Development of high-rise buildings: digitalization of life cycle management
}

\author{
Elena Gusakova ${ }^{1, *}$ \\ ${ }^{1}$ Moscow State University of Civil Engineering, Yaroslavskoe shosse, 26, Moscow, 129337, Russia
}

\begin{abstract}
The analysis of the accumulated long-term experience in the construction and operation of high-rise buildings reveals not only the engineering specificity of such projects, but also systemic problems in the field of project management. Most of the project decisions are made by the developer and the investor in the early stages of the life cycle - from the acquisition of the site to the start of operation, so most of the participants in the construction and operation of the high-rise building are far from the strategic life-cycle management of the project. The solution of these tasks due to the informatization of management has largely exhausted its efficiency resource. This is due to the fact that the applied IT-systems automated traditional "inherited" processes and management structures, and, in addition, they were focused on informatization of the activities of the construction company, rather than the construction project. Therefore, in the development of high-rise buildings, the tasks of researching approaches and methods for managing the full life cycle of projects that will improve their competitiveness become topical. For this purpose, the article substantiates the most promising approaches and methods of informational modeling of high-rise construction as a basis for managing the full life cycle of this project. Reengineering of information interaction schemes for project participants is considered; formation of a unified digital environment for the life cycle of the project; the development of systems for integrating data management and project management.
\end{abstract}

\section{Introduction}

Construction and operation of high-rise buildings is one of the most complex types of real estate development. Project ideas of high-rise construction are always unique and always connected with the development trend of megacities. To date, sufficient experience has been gained not only in the design and construction of such buildings, but also the data of their long-term operation and monitoring in Russia and many other countries [1, 2]. Bright examples of the implementation of such projects in Moscow are seven buildings of "Stalin" skyscrapers, the construction of the New Arbat, a complex of high-rise residential, hotel and office complexes of the business center "Moscow City".

Analysis of the experience of high-rise construction shows that the more high-rise buildings are built, the longer buildings are used, the more their engineering and

\footnotetext{
*Corresponding author: e_gusakova@inbox.ru
} 
organizational-technological specifics are revealed. It is associated with large volumes of long-term investments for new construction, for the preparation of the territory, and for the coordination of relevant legal, regulatory procedures, financial relations and legal and urban issues [3]. Specificity is associated with the complexities and risks that almost all participants in high-rise construction projects - customers, investors, designers, builders, operators, expect [4]. The customer and the investor are certain risks of long-term forecasting of future costs and project management, designers have difficulty in accounting for specific loads (sediment, wind, terrorist attacks, fire, etc.), builders - each time the development of new organizational and technological solutions . At the operational stage the complexity of the management company in ensuring the reliable operation of engineering networks and the safety of the facility. In a high-rise building of a heating, ventilation, air-conditioning, heat supply and cooling system and other engineering systems - this is a very complex set of interconnected functional systems of equipment and utilities. In addition, the operation processes of each high-altitude object are unique. This is due to the fact that high-rise buildings are multifunctional, they have functional areas in various combinations: residential, administrative-office, hotel, car parks, various technical rooms, shops, restaurants, cafes, entertainment public spaces for meetings, exhibitions, etc.

Meanwhile, the unique risks associated with high-rise projects lie not only in solving engineering and technical problems. System gaps and uncertainties in management are found, primarily in the life cycle management concepts projects. And this is quite understandable. All decisions that determine the purpose of the high-rise construction project, the functionality of the building, profitability, partners, organizational and economic mechanisms for selling and disposing of property are accepted by the customer and the investor at the early stages of the life cycle - from the acquisition of the site to the sale of the high-rise building [5]. Therefore, initially the majority of participants in the construction and operation of a high-rise building are far from the strategic management of the project life cycle.

\section{Methods}

It is obvious that high-rise construction projects require the development of a strategy for organizing and coordinating the stages and stages of construction and maintenance. The forecast of the life cycle of a high-rise development project is far from simple. This is a large amount of information on the project, for processing which, as experience shows, not enough computer technology alone. These issues are a separate, specific area of research that requires developers and architects, designers, engineers, ecologists, sociologists, demographers, representatives of different layers of the urban community to carry out a multifaceted and professional analysis of the project life cycle.

It should be understood that the approach to creating a digital environment for building projects was evolving. First, tools and systems for automating the production of paperbased documentation were created and widely introduced: computer-aided design systems for the production of drawings, specifications, and technological documentation. Then - the automated production management system for creating production plans and reports on its progress, office systems - for the preparation of text and table documents, etc. And it was natural, because for many decades the paper documentation was the generally accepted form of presenting the results of intellectual activity and the instrument of information interaction. Most of the existing management processes, as well as organizational, production and management structures were formed based on it. Until now, thousands of designers, engineers, designers, technologists, manufacturers, managers, employees of management companies and commercial structures are engaged in the development, distribution, storage and actualization of out-of-mass information files. Many participants 
of the project are brought up on standards, norms, rules and schemes, which are based on case management using paper documentation [6].

In the case of high-rise construction projects, as with most complex projects, the traditional approach to informatization has practically exhausted its efficiency resource to date. Restriction is the "inherited" project management structures that use only a small fraction of the potential of information and network technologies [7]. Practice has shown that the automation of the production of traditional paper documents does not solve not only the management problems, but also the more simple tasks of information exchange between numerous participants in the life cycle of a complex high-rise construction project (customers, designers, builders, operating and maintenance organizations, etc.). Different systems "speak different languages" and do not understand each other well. Information structures and systems were developed both from above and from below, on various principles of data structuring and software, which creates difficulties for the exchange of electronic data, complicates the integration of the information environment. When transferring data from one information system to another, it takes a lot of labor and time to unify data structures and re-encode, which fundamentally reduces the effectiveness of IT systems. Problems of digitalization of project life-cycle management are also related to the fact that the development of IT-systems is focused on informatization of the activities of the construction company, rather than the project. Features of the life cycle of the project are associated with a large number of project participants, the presence of highly complex, multidirectional and multi-criteria relationships: the investor - the customer of construction - the general contractor - subcontractors; specificity of cash flow associated with procurement of materials and equipment, hiring of labor, permanent relocation of workers from one construction site to another, etc. [8]. For this reason, it is difficult to accumulate and ensure the continuity of data on the stages and subsystems of the life cycle of a highrise building. The developer, acting to achieve tactical and strategic design goals(developing the organizational and economic mechanism for the implementation of the project, planning the work and the timing of their implementation, the need for labor, resources, resources and resources, coordinating the scope of work with the customer and the contractor and other participants, etc.), constantly faces the uncertainty of the life cycle of the project and conflicting management tasks. At the same time, he must solve them in the absence of an organized information space for the project and decision support systems [9].

\section{Results}

Thus, the potential for improving the life cycle management of high-rise construction projects is largely exhausted, due to two problems:

- Methodological approach to computerization, which automates the activities of project participants and the processes of organizational, production and management structures, which until then were formed in the context of traditional workflow, is outdated;

- Specifics of construction, where the goal is a project (building, construction, real estate in general). Most software systems do not take this into account to the extent necessary, since they are developed by analogy with other industries for the needs and business processes of a manufacturing enterprise, construction firm or company. Those informatization in construction is not project-oriented [11].

\section{Discussion}

To solve these problems, new concepts of control digitalization, based on: 
1. the formation of a single digital environment for the full life cycle of a high-rise construction project, which should reveal the potential for strategic management, taking into account the features of the facilities.

2. organizational reengineering of schemes of information interaction of project participants.

The progressive approach to informatization, to the structuring of data, their storage, archiving and updating, is based on constant information support of the life cycle of the project. All transformations of a real building object in time must be accompanied by changes in the data about it. Technical support of information systems, including means of collection, registration, accumulation, processing, transmission, display, output of information; devices for automatic information retrieval, communication and computer networks allow it to be carried out practically in real time. Ideally: the real building object is accompanied by its digital copy or virtual building object, which continues to exist and is updated at the stage of building operation. It can be realized in an integrated digital environment of the project, which ensures, under the condition of observing common standards, the sharing and continuity of information at all stages of the project's full life cycle [12].

The interplay of high-rise construction participants can also become more effective if it is implemented in the integrated digital environment of the project life cycle. First, during the construction phase, intensive exchange of results between project, survey and construction organizations, including the customer, the general contractor, subcontractors, suppliers and other project participants, often geographically separated from each other and using incompatible computer platforms and software, is needed. Then - at the stage of operation of the high-rise building. The life cycle of high-rise buildings has been realized for many decades, including possible upgrades, reconstruction or redevelopment, and, if necessary, the liquidation of a project that has exhausted its potential. Almost all projects are subject to repeated changes in the concept of the project and redevelopment. Changes are inevitable in the implementation of long-term projects. The need for changes arises during the life cycle of a building repeatedly and practically at any stage. Accordingly, there is a need for technology change management. They include long-term planning of the investment and construction process, consideration of the cyclic patterns of macroeconomics in the high-rise building, much more complex project analysis and consolidation of the stages and participants of the project. In practice, setting and solving such problems can only be achieved by large specialized development companies. But as a result, the adaptability of the project increases, which makes it easier to manage changes and is determined directly by the extent to which the most probable changes and directions of development of high-rise building project subsystems were provided for in the design decisions.

At each stage the project can be reflected by a completely unambiguous information object and model. During the life cycle, the initial model is sequentially detailed, new subsystems appear, the amount of data increases. Accordingly, the full life cycle of a highrise building project can be represented as a boundedly increasing sequence of interconnected information objects. The tree of the project objectives and the direction of development are determined by its participants. At any stage of the life cycle, the information object or model of the project is an integrated environment for the formation of the composition of the work of this stage (where it is determined what exactly it is necessary to design, produce, mount, repair, re-equipment, what is the laboriousness of the work, performers, costs, etc.).

Management of changes from this point of view is methodologically close to genesis as a method of research. Genesis focuses on the future of the project, considers it as a developing system, all the characteristics of which are due to cause-effect relationships and 
are adequate to changing external conditions and factors of influence. Substantiation of solutions by methods of organizational and technological genesis is the initial condition of the project's fitness for changes, its adaptability [13]. Dynamic classes of models can be used for this. Traditional project analysis can be supplemented by taking into research feedbacks and information flows obtained on the basis of predicting the regularities and parameters of the life cycle of a project at pre-investment stages.

The analysis of the software of construction companies and developers shows that the creation of a integrated information model of the life cycle of a high-rise building is possible on the basis of integration and subsequent consolidation of data management systems and project management, i.e. PDM (Product Data Management) and PM (Project Management) classes. The functions of the PDM-system are to ensure the reception of data and provide tools at each stage to form the composition of the works, the functions of the PM system - to formulate a plan of these works at each stage. At the same time, the process of data exchange between PDM and PM, including the transformation of production problems into informational ones, should be convenient for work in an iterative mode for all project participants.

The analysis of the accumulated experience shows that the BIM (Building Information Modeling) technologies and CALS (Continuous Acquisition and Life Cycle Support) technologies play a special role in solving the problems considered.

BIM-technology can be used as a basis for creating software-compatible formats for data modeling of high-rise buildings. In practice, BIM is used for the most part to visualize design solutions and present them to the customer. Its use with respect to the full life cycle is limited to a low level of development of the classification of objects, works and resources in construction and, as a result, low compatibility of data formats.

The idea of information support of projects and information integration of the stages of the product life cycle formed the basis of CALS technologies (Continuous Acquisition and Life Cycle Support). This idea consists in abandoning the "paper environment", which traditionally reflects the development and sale of products, and the transition to an integrated information environment covering all stages of its life cycle. Information integration is the result of the fact that all automated systems used at different stages of the project life cycle do not operate with traditional documents (for example, scanned drawings) or even with their electronic displays, but with formalized information models describing the product, its production technologies and use. Models exist in an integrated information environment in the form of information objects. As necessary, those systems that need specific information objects for work can extract them, process them, create new objects, and place their work results in the same environment. It is a collection of distributed databases in which there are unified, standard rules for storage, updating, retrieval, and transmission of information through which paperless information interaction takes place between all participants in the product life cycle.

The integrated digital project life cycle includes a full set of indicators, documents, classifiers and codifiers of information, files, databases, knowledge bases, methods of using them in the subject activity, as well as the methods of representation, accumulation, storage, transformation, a specific system to meet the information needs of users in the right form and at the required time. At the same time, information, once created, is stored in a single digital lifecycle environment, is not duplicated, does not require any transcoding in the exchange process, preserves its relevance and integrity. In order to make all this possible, information models and corresponding information objects should be standardized, including modeling tools, exchange file formats, program interfaces for access to shared data, application protocols - product data models.

For the leading industries (mechanical engineering, aerospace industry, which produce the same type of products), the international community has developed standards STEP 
(from the English STandard for Exchange of Product model data. The content and organization of information objects is determined by the features of the domain and the information needs of users of the automated system, their goals and objectives. At the same time in high-rise construction each object is unique, which significantly complicates and increases the cost of creating compatible data formats.

\section{Conclusions}

Thus, managing the life cycle of a high-rise development project is an urgent task that requires serious scientific and project research. Traditional schemes for managing the life cycle of the project and the interaction of all participants in the high-rise construction project should be substantially modernized in the context of Building Information Modeling and Continuous Acquisition and Life Cycle Support. At the same time, the development of systems for integrating data management and project management will ensure a multiple increase in the efficiency and competitiveness of a high-rise building project at all stages of its life cycle.

\section{References}

1. E. Gusakova International Scientific and Technical Journal "Real Estate: Economics, Management", 2, 61-66 (2009)

2. A. Orlov, Economics and Entrepreneurship, 6-3 (59-3), 545-548 (2015)

3. P. Grabovyi, E. Gusakova, S. Lunyakov International scientific and technical journal "Real Estate: Economics, Management", 3-4, 74-79 (2014)

4. S. Baronin, A. Porshakova Journal of Izvestia of the Penza State Pedagogical University, 24 (2011)

5. E. Gusakova, Yu. Ushakova International Scientific and Technical Journal "Real Estate: Economics, Management", 1, 54-60 (2015)

6. T. Kuz'mina, S. Sinenko, A. Slavin Industrial and civil engineering, 6, 71-75 (2016)

7. A. Pavlov, E. Gusakova Fundamentals of organization and management in construction (Publishing house URAIT, 2016)

8. A. Volkov,V. Chulkov, D. Korotkov Advanced Materials Research, 2577-2580 (2014)

9. A. Khripushin, A. Ginzburg Vestnik MGSU. 3, 207-211 (2013)

10. A. Volkov, P. Chelyshkov D. Lysenko Procedia Engineering 153, 833-837 (2016)

11. A. Ginzburg Industrial and civil engineering, 9, 61-65 (2016)

12. E. Gusakova, A. Krugina Real Estate: Economics, Management", 32, 84-87 (2012)

13. A. Ginsburg Information Resources of Russia, 5, 28-31 (2016) 